\title{
NADERE SIRIPOEAN-GEGEVENS
}

DOOR

H. T. DAMSTÉ

(Met 14 foto's.)

Kort na de verschijning van mijn Islām en Siripoean-artikel in deel 100 der Bijdragen, verraste professor dr V. E. Korn mij met drie indertijd van collega O. Horst, toenmaals assistentresident te Bima, ontvangen siripoean-foto's.

De heer Horst zelf, thans te Haarlem, verschafte mij sedert méér foto's nog, mèt eenige toelichting. Hij had het feest éénmaal meegemaakt, in 1928 of '29, en toen was er op de gevoelige plaat het eenenander van vastgelegd. Plaatjes en inlichtingen, welke de heer Horst zoo vriendelijk was mij te verstrekken, mogen hieronder volgen.

Afbeeldingen 1, 2 en 3 vertoonen hoogwaardigheidsbekleeders van Bima in adat-uitrusting. Op 1 zijn 't vier rato's; $n^{\circ} 2$ geeft den Rato Renda (hoofd van de politie) en Boemi Loema Bolo; $\mathrm{n}^{\circ} 3$ den penghoeloe van kampong Melajoe met vier onder zijn hoede staande dansjongens (waarvan de eerste zonder gezicht en de vierde ook incompleet). Een van die jongens staat afzonderlijk - van voor en van opzij - afgebeeld op 5 en 7 , terwijl 4 en 6 beeltenissen geven van een danseres. $N^{\circ} 8$ toont vier danseressen, die ten paleize-Bima haar kunst ten beste geven voor den soeltan en diens westersche gasten.

Op $\mathrm{n}^{\circ} 9$ zien wij de Werasche ruiterij, die een vertooning geeft; op $\mathrm{n}^{\circ} \mathrm{s} 10 \mathrm{t} / \mathrm{m} 14$ de door vele schouders gepikelde baar met koebah en dansende en niet-dansende ,opgezetenen”, steeds nader komend.

Volgen eenige toelichtende mededeelingen.

Wat er met de baar na afloop van het feest gebeurt, - of die wordt verbrand, in zee geworpen, geplunderd of hoe en wat - de heer Horst kon daaromtrent geen inlichting verstrekken; maar over de constructie teekent hij het volgende aan:

„De koebah is een uit bamboe (latten en vlechtwerk) samenge,steld vierkant huisje ter grootte van $\pm 4 \times 4$ meter, bevestigd op ,een horizontaal geraamte, waaraan het kan worden gedragen. Op ,,de vloer is aan de vier zijden een balustrade opgetrokken van ge-

D1. 101. 
,"vlochten bamboe ter hoogte van $1 / 2$ meter en verder zijn de zijkanten ,open. Het vierzijdig dakgeraamte is boven voorzien van één ge,leding, een onderbreking van het dak zooals de toempangs van een ,,meroe, en beide deelen zijn met doek afgedekt in drie banen. De „foto toont aan dat er drie banen van verschillende kleur zijn, doch , ,ik kan mij slechts de kleuren rood en wit herinneren. De dakspits ,draagt een versiering van twee boven elkaar geplaatste kegels en de ,dakriggels dragen aan hun ondereind nagemaakte bloemversieringen, , ,de door U genoemde poean-tuilen. De vloer is bedekt met matten en „,kleeden en in het midden staat een groote poean-tuil. Aan één der ,zijden wordt door een in de koebah zijnde persoon een (gele?) ,pajong naar buiten uitgestoken vastgehouden".

Over het dansen zegt de heer Horst:

„In de rondgedragen koebah bevinden zich de vier maagden en „,vier knapen in feesttooi, die dansen uitvoeren; een paar oudere ,,vrouwen zijn aanwezig om het dansen te regelen en om te zorgen , dat kleeding en verdere uitrusting der danseressen in orde blijven.

„De knapen en meisjes dansen op de muziek van het orkest, dat ,er achter loopt; het dansen is meer een plechtig bewegen van armen „en handen en schuivende passen, zooals bij het menari.

„Zooals de foto's aantoonen, zijn dansers en danseressen fraai uit,gedost, en opvallend zijn de moesjes op gezicht en armen en bij de „,knapen ook op de bloote borst aangebracht; deze zijn van een gelijk,soortige figuur als de op het door de meisjes gedragen jak en op de ,,door de jongens gedragen doek geborduurde bloemetjes.

„Bij het dansen maken de danseressen gebruik van een waaier en „,de dansers van de doek welke in rust om het gevest van de kris is ,geknoopt".

Ik lees verder :

„Ik kan mij niet herinneren, dat de soeltan van Bima zich in de „,koebah heeft laten dragen met de dansers en danseressen gedurende ,den rondgang. Overigens hadden bij het door mij bijgewoonde siri,poeanfeest ook de vertooningen plaats van de Wera'sche ruiterij, „,de krijgsdansen met schild en speer der adathoofden etc.".

Over de beteekenis van ,poean" merkt de heer Horst op:

„Filet's plantkundig woordenboek voor Ned.-Indië geeft s.v. poeän ,,$(M)=$ clerodendron inerme Gaertn., verwijst naar $\mathrm{n}^{\circ} 1046$ en ,,beschrijft deze daar als een heester, door geheel Indië verbreid, ,,veelal in tuinen.

„Heyne: De nuttige planten van Ned:-Indië, deel IV p. 120, ver- 


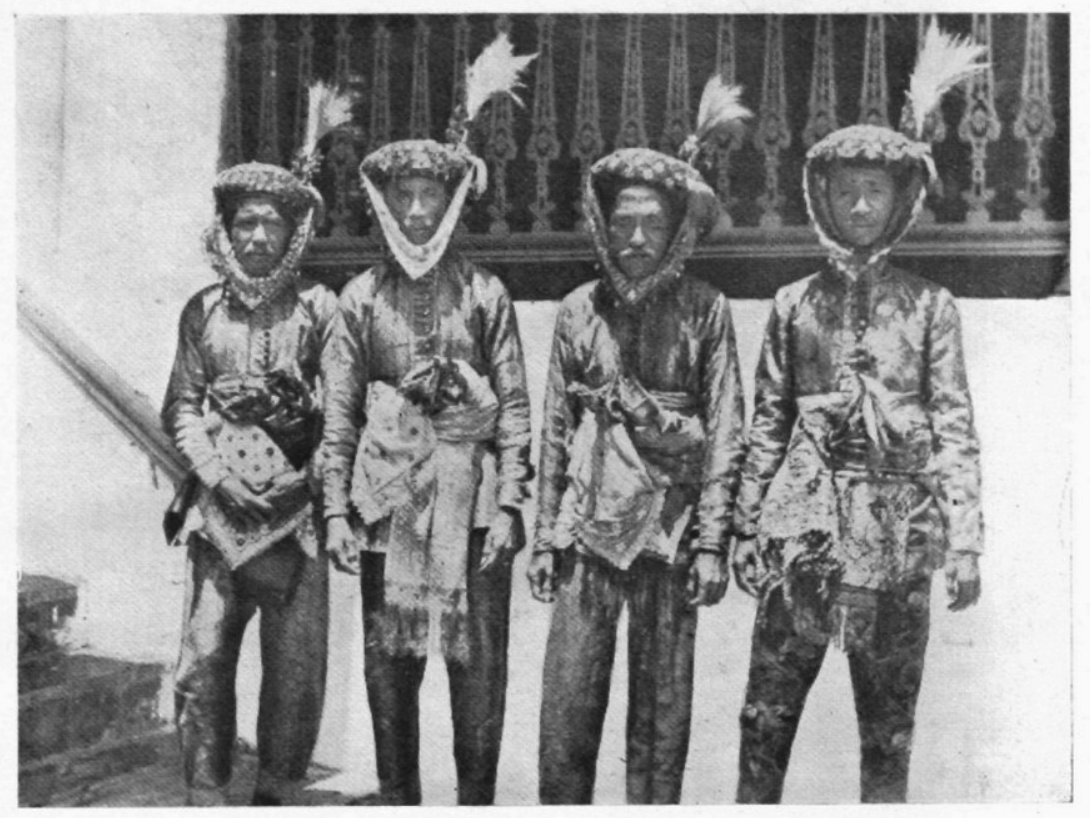

1.

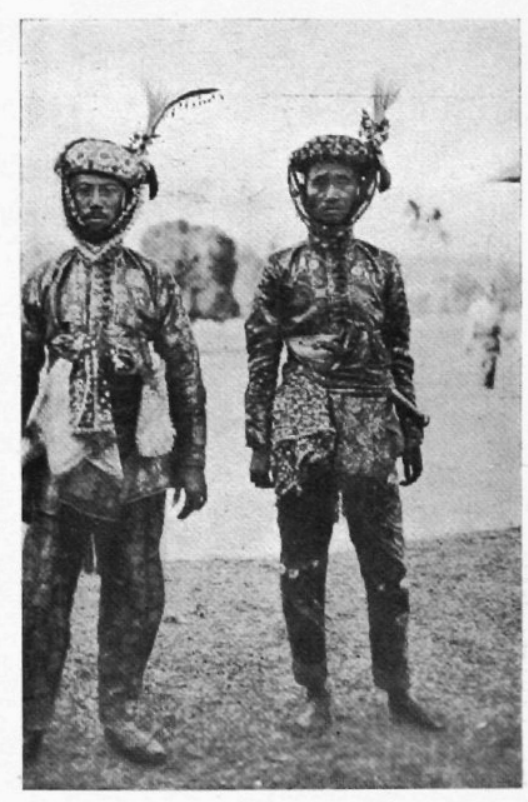

2.

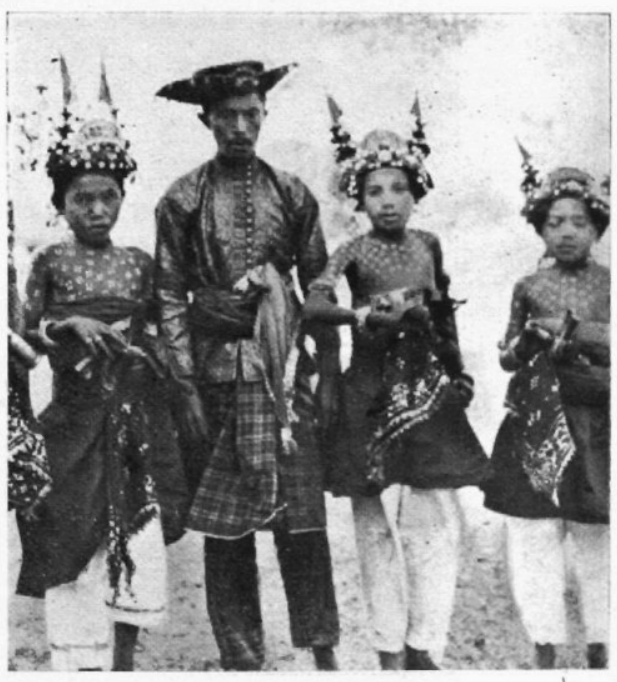

3. 


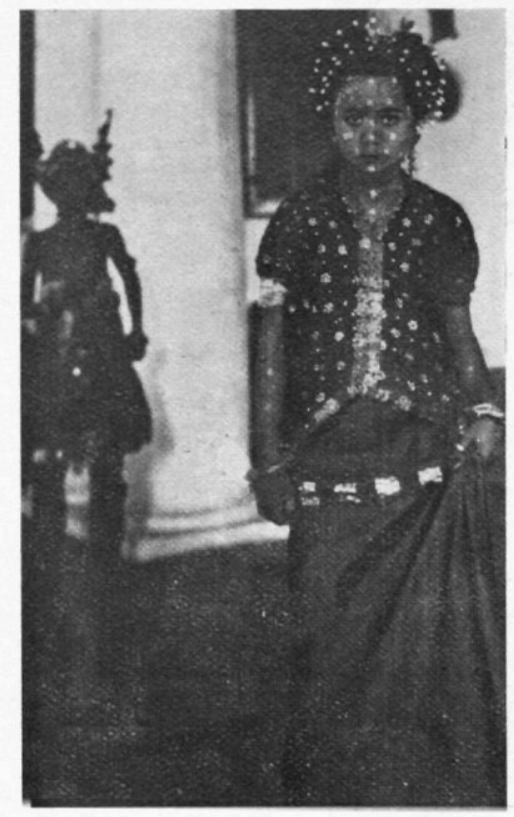

4.

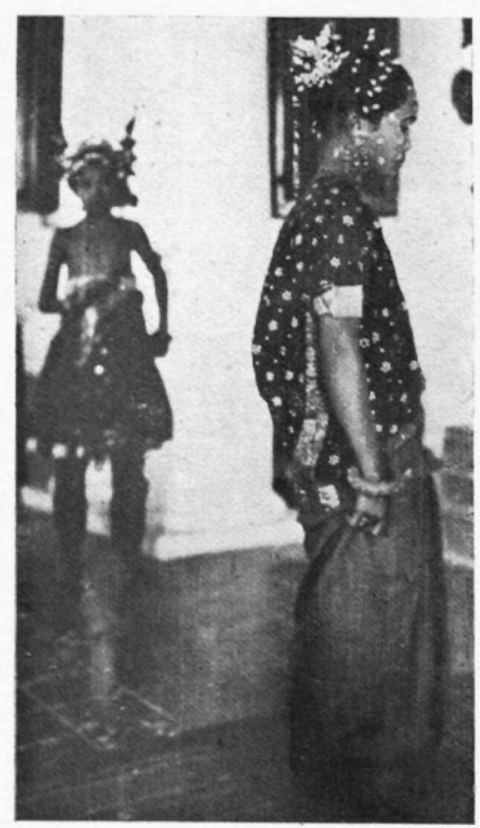

6.

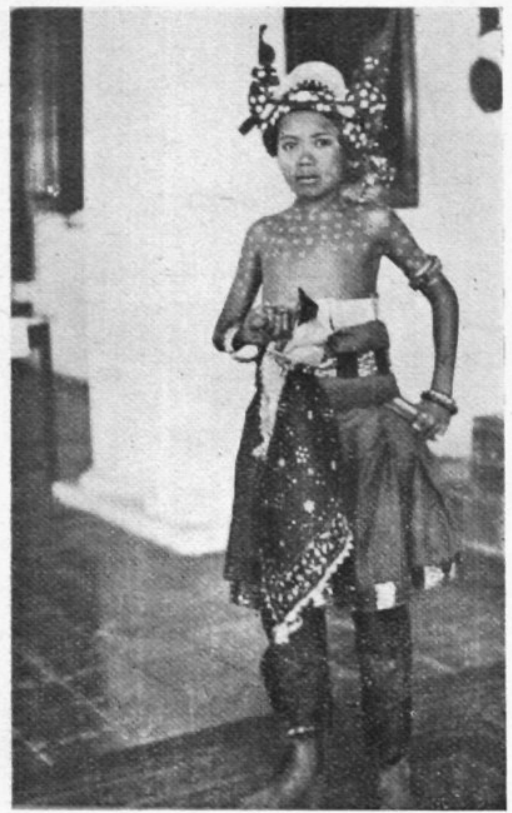

5.

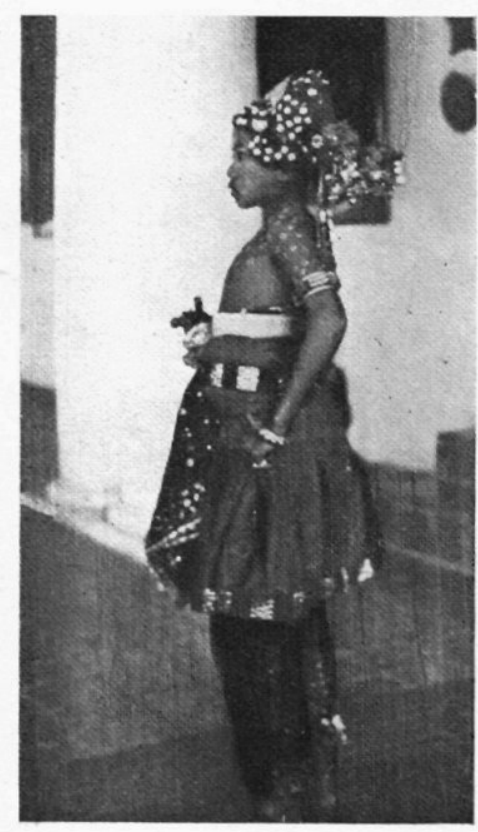

7.

Downloaded from Brill,com@4/26/2023 01:19: 02PM 


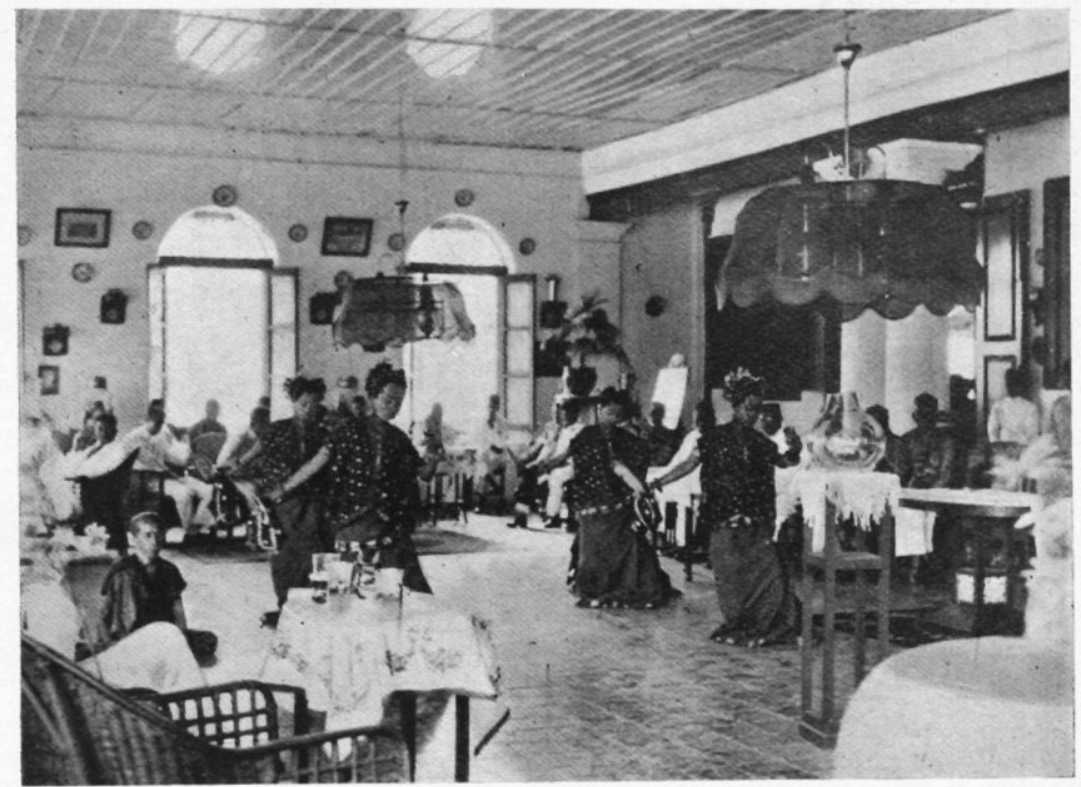

8.

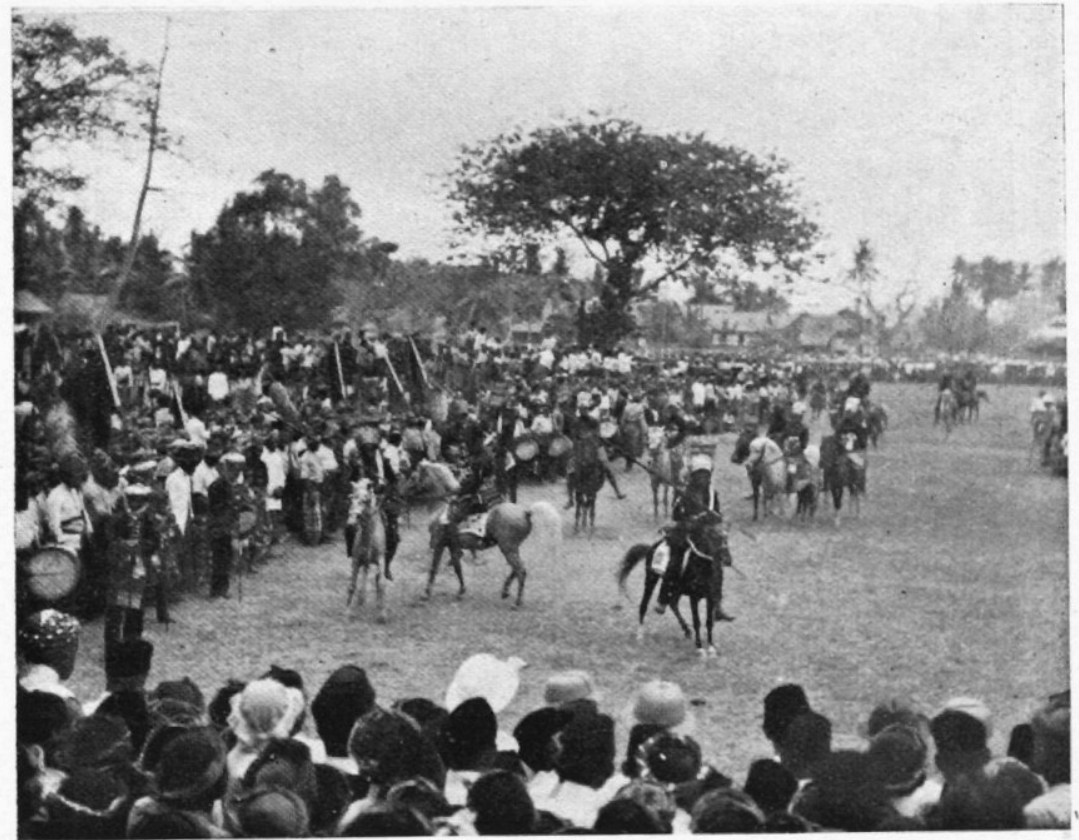

9.

Downloaded from Brill.com๑4/26/2023 01:19:02PM via free access 


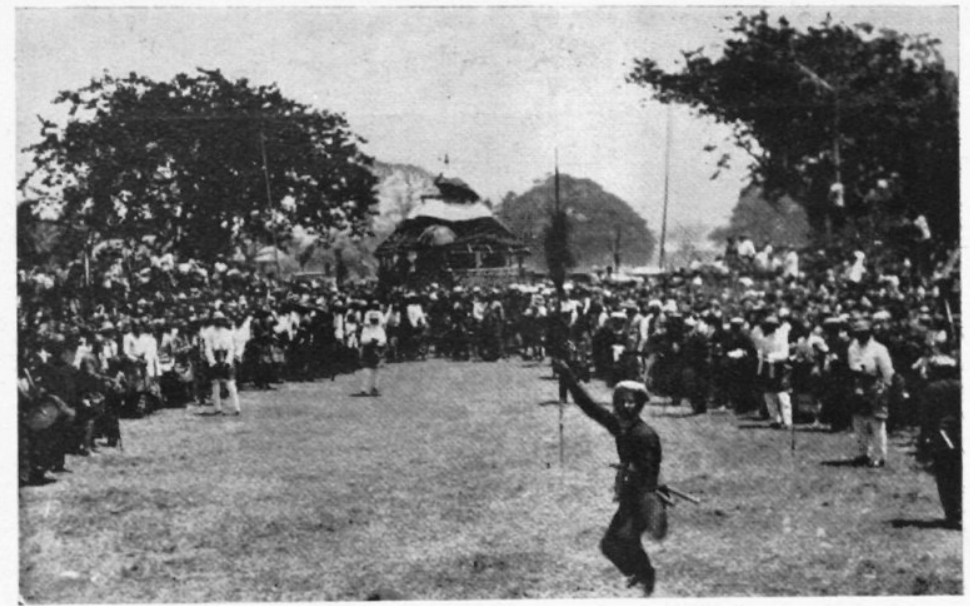

11.

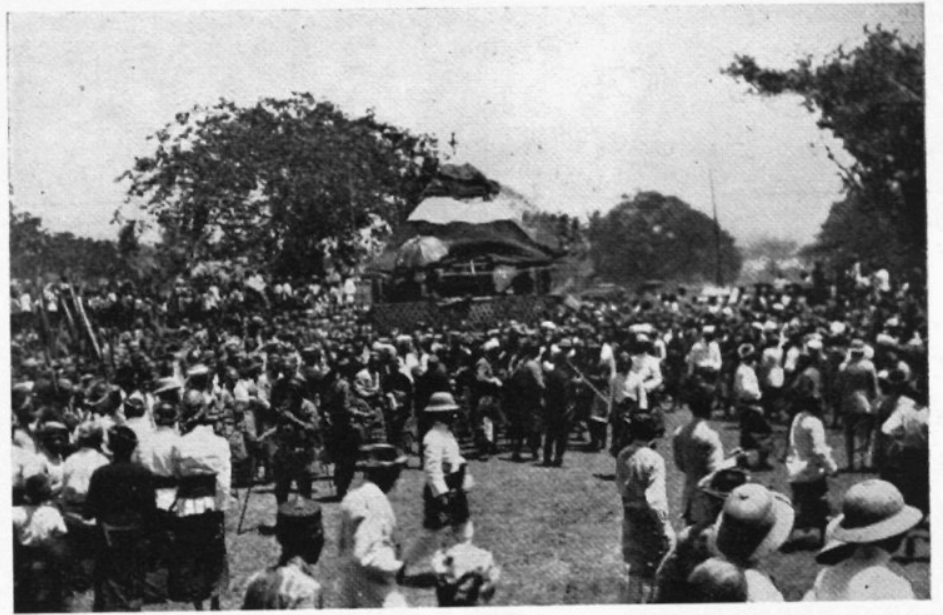

12.

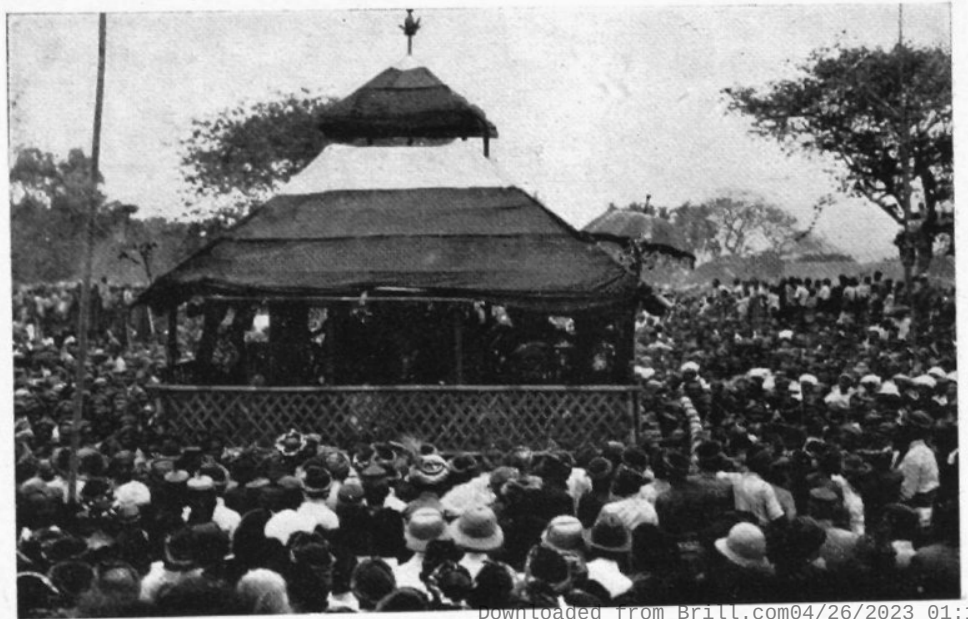




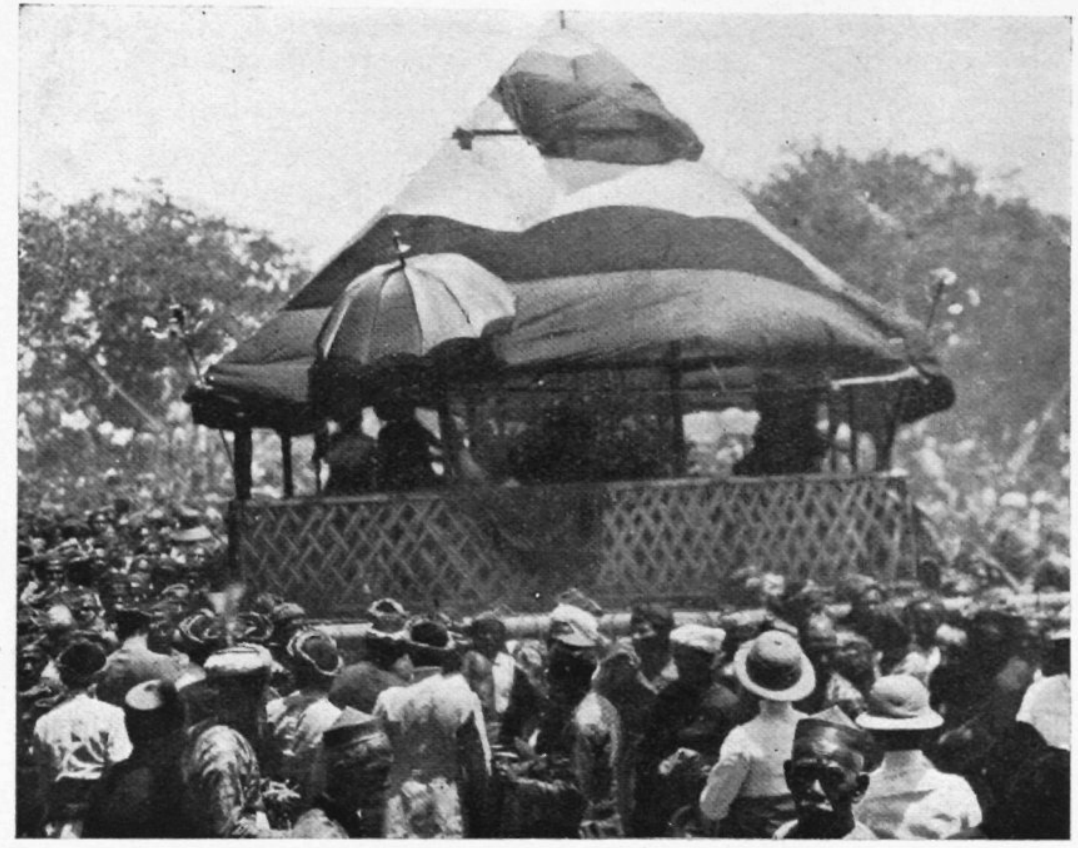

13.

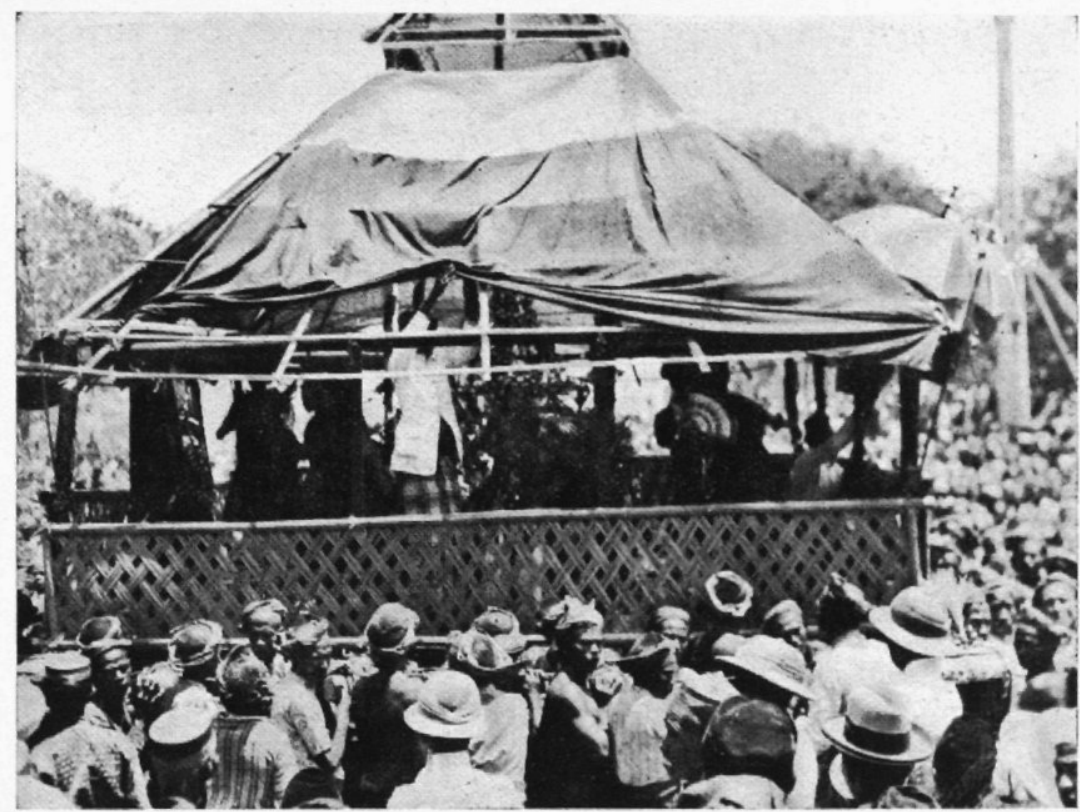

14. 
„,meldt bij clerodendron inerme Gaertn. : heester 1 tot 10 meter hoog, ,,alleen groeiend aan of nabij zout of brak water, vooral aan rivier„,monden en in de mangrove, minder vaak aan zandig strand, en haalt ,,aan, dat Rumphius hem beschrijft als een struik, die bij de visschers ,,in hooge achting staat als heilzaam tegen allerlei vergiftiging door ,visschen en andere zeedieren.

„Den naam boenga poean echter kent Heyne toe aan een andere „clerodendron nl. de clerodendron Rumphianum, een heester op Am,bon in de hoven en boschtuinen als sieraad geplant.

„Indien poean (siripoean) op een plant (bloem) is terug te voeren, ,lijkt het mij waarschijnlijk, dat daarmede de meer algemeen voor„,komende clerodendron inerme Gaertn. is bedoeld. Houdt het bezigen ,van poean-tuilen bij dit feest, aangenomen dat deze inderdaad de ,,bedoelde heester vertegenwoordigen, dan wellicht verband met de ,, door de Bimasche kustbevolking daaraan toegekende heilzame krach„ten? Het zou de moeite waard zijn dit eens ter plaatse na te gaan”.

Inderdaad, dit en meer valt ter plaatse na te gaan! Moge 't daar spoedig toe kunnen komen!

Intusschen zijn wij den heer Horst zeer dankbaar voor zijn fotografische bijdragen en de daarbij gegeven toelichtende aanteekeningen. 